\title{
Estimated Central Blood Volume in Cirrhosis: Relationship to Sympathetic Nervous Activity, $\beta$-Adrenergic Blockade and Atrial Natriuretic Factor
}

\author{
Jens H. Henriksen, ${ }^{1}$ Flemming Bendtsen, ${ }^{2}$ AleXander L. Gerbes, ${ }^{4}$ Niels Juel Christensen, ${ }^{3}$ \\ HELMER RING-LARSEN ${ }^{2}$ AND THORKIID I.A. SøRENSEN ${ }^{2}$ \\ Departments of ${ }^{1}$ Clinical Physiology and ${ }^{2}$ Hepatology, Hvidoure Hospital, University of Copenhagen, DK-2650 Huidoure;

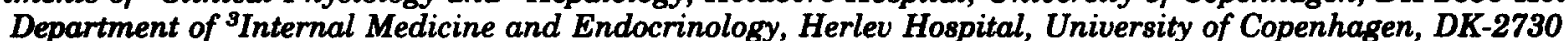 \\ Copenhagen, Denmark; and "Department of Medicine II, Klinikum Grosshadern, Ludwig-Maximilian University, \\ D-8000 Munich, Germany
}

The extimated central blood volume (i.e., blood volume in the heart cavities, lungs and central arterial tree) was determined by multiplying cardiac output by circulatory mean transit time in 19 patients with cirrhosis and compared with sympathetic nervous activity and circulating level of atrial natriuretic factor. Arterial norepinephrine level, an index of overall sympathetic nervous activity $(3.08 \mathrm{nmol} / \mathrm{L}$ in patients ve. $1.36 \mathrm{nmol} / \mathrm{L}$ in controls; $p<0.01$ ) was negatively correlated $(r=-0.54, p<0.01)$ with estimated central blood volume (mean $=23 \mathrm{ml} / \mathrm{kg}$ in patients ve. $27 \mathrm{ml} / \mathrm{kg}$ in controls; $p<0.05$ ). Similarly, renal venous norepinophrine level (an index of renal sympathetic tone; $4.26 \mathrm{nmol} / \mathrm{L}$ in patients vs. 1.78 $\mathrm{nmol} / \mathrm{L}$ in controla; $\mathrm{p}<0.01$ ) was inversely correlated with estimated central blood volume $(r=-0.58$, $\mathrm{n}=18, \mathrm{p}<0.02)$. No aignificant correlation could be entablifhed between arterial atrial natriuretic factor level $(8.9 \mathrm{pmol} / \mathrm{L}$ in patients $\mathrm{v} 8.9 .6 \mathrm{pmol} / \mathrm{L}$ in controls; not aignificant) and estimated central blood volume. Hemodynamic values were subsequently modifled with oral propranolol (80 mg). During B-adrenergic blockede, the mean estimated central blood volume was not altered aignificantly, except in six patients who exhibited decreases in mean arterial blood preseure (85 to $69 \mathrm{~mm} \mathrm{Hg}, \mathrm{n}=6$ ) and decreases in mean estimated central blood volume $(23.2$ to $20.6 \mathrm{ml} / \mathrm{kg}$; $\mathrm{n}=6, \mathrm{p}<0.06$ ). Slight increases were observed in moan right atrial preseure $(2.2$ to $3.7 \mathrm{~mm}$ Hg; $n=14$, p $<0.05$ ); this change was positively correlated with the change in estimated central blood volume ( $\mathbf{r}=0.44, \mathrm{n}=14, p=0.06)$. In conclusion, reduced estimated central blood volume probably "unloads" volume receptore and baroreceptors, thus provoking enhanced overall and renal sympathetic nervous ac-

Received September 26, 1991; accepted June 29, 1992.

This atudy was supported by grants from The Danish Medical Research Foundation, the NOVO Foundation, the John and Birthe Meyer Foundation and the Deuteche Forschungsemeinschaft (Ge 576).

Address reprint requests to: Jens H. Henriksen, M.D., Department of Clinical Phyziology, 239, Hvidovre University Hospital, DK-2650 Hvidovre, Copenhagen, Denmart.

$81 / 1 / 40011$ tivity and thereby contributing to increased water and ealt retention in cirrhosis. During $\beta$-adrenergic blockade estimated central blood volume changes correlated with alterations in preload and afterload. These findings indicate that central circulatory and arterial underfilling is a key element of the hemodynamic derangement obeerved in cirrhosis. (HFPATOLOGY 1892;5:1163-1170.)

We recently found that the estimated central blood volume (ECBV; i.e., blood volume in the heart cavities, lungs and central arterial tree) is decreased in patients with cirrhosis $(1,2)$, indicating a reduced "effective" blood volume. It has been postulated that central hypovolemia is responsible for the activation of the sympathetic nervous system and alterations in other homeostatic regulators, including atrial natriuretic factor (ANF), in these patients (3-7), but no study has addressed that question directly.

Systemic and splanchnic hemodynamic values are altered during $\beta$-adrenergic blockade: reductions in portal venous pressure and cardiac output and increases in peripheral vascular resistance and right atrial pressure are seen. Because the ECBV may be determined with these variables $(1,2)$, we decided to measure ECBV after propranolol intake.

This study was undertaken to assess the relationship between ECBV, systemic and portal hemodynamics and markers of overall and renal sympathetic nervous activity. We measured the ECBV and the circulating and renal venous levels of norepinephrine, arterial epinephrine and ANF before and after $\beta$-adrenergic blockade in patients with cirrhosis and esophageal varices who were undergoing hemodynamic investigation.

\section{PATIENTS AND METHODS}

Study Population. Nineteen patients (17 men) with biopsyverified cirrhosis were referred for hemodynamic investigation. All patients had endoscopically verified esophageal varices; none had experienced bleeding episodes. Liver disease was caused by alcohol in 18 patients and was posthepatitic in 


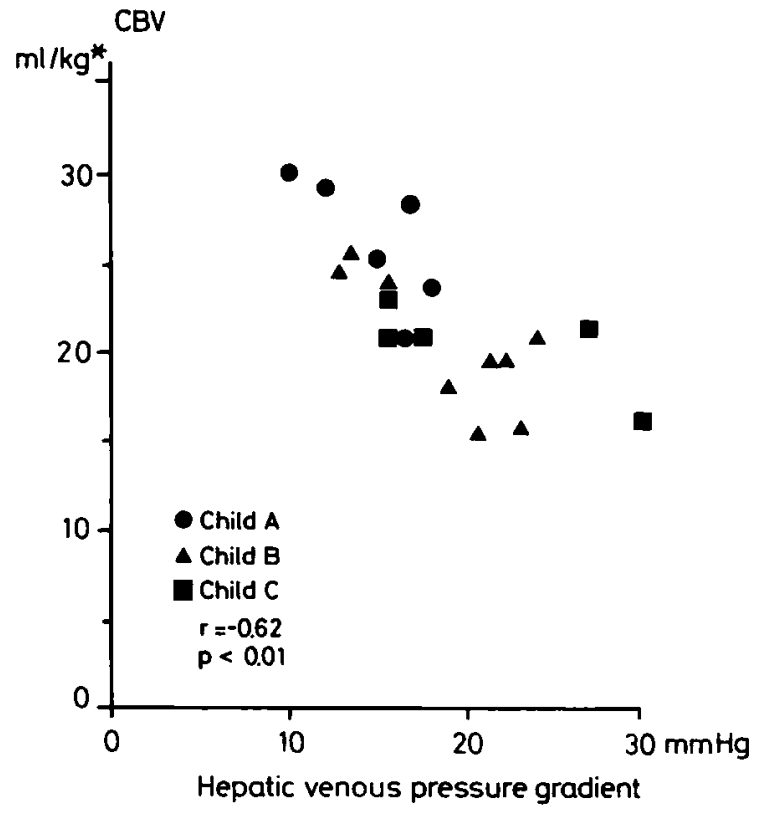

FIG. 1. Relationship between ECBV and hepatic venous pressure gradient.

one. The age range was 30 to $69 \mathrm{yr}$ (mean $=58 \mathrm{yr}$ ). None of the patients had encephalopathy worse than grade 1 . All were abstaining from alcohol intake and were without withdrawal symptoms at the time of study. Six patients were in ChildTurcotte group A, eight were in group $B$ and five were in group C. Ultrasonography showed the presence of ascites in 11 patients. Patients without ascites had no dietary restrictions, whereas those with ascites were prescribed a $40 \mathrm{mmol}$ sodium/day diet. In the group of patients with ascites, 11 received spironolactone ( $100 \mathrm{mg} /$ day $)$, as monotherapy in 1 and in combination with bumetanide, 1 to $8 \mathrm{mg} /$ day, in 10 . Biochemical test values are summarized in Table 1 . The mean height was $170 \mathrm{~cm}$ (range $=163$ to $182 \mathrm{~cm}$ ), the mean body weight was $68 \mathrm{~kg}$ (range $=54$ to $85 \mathrm{~kg}$ ) and the mean body surface area was $1.82 \mathrm{~m}^{2}$ (range $=1.61$ to $2.18 \mathrm{~m}^{2}$ ).

Sixteen subjects (12 men) who were without abnormal findings (normal volunteers, $\mathrm{n}=3$; functional heart murmur, $\mathrm{n}=3$ ) or had only minor disorders (fatty liver, $n=8$; fibrosis without cirrhosis, $n=2$ ) served as controls for ECBV determination (2). The control patients were fitted with catheters to rule out organic heart disease or portal venous hypertension. None showed evidence of organ failure or fluid accumulation, and all had normal chest appearance on x-ray, normal EKGs and normal levels of serum creatinine and electrolytes. Their age range was 37 to $76 \mathrm{yr}$, their body height range was 160 to $180 \mathrm{~cm}$, their body weight range was 42 to $99 \mathrm{~kg}$ and their body surface area range was 1.40 to $2.17 \mathrm{~m}^{2}$.

Nine other subjects served as controls for assay of arterial and renal venous catecholamines (eight were men; six of these subjects were normal volunteers, two had fatty liver and one had a functional heart murmur). Their ages ranged from 22 to 52 yr (5). The controls for assay of circulating ANF were eight people (four women) with no abnormal hemodynamic findings (three had irritable bowel syndrome and one each had intercostal neuralgia, myositis, postcholecystectomy pain and persistent hepatitis and fatty liver); they were fitted with catheters to rule out portal hypertension or mesenteric ischemia. Their ages ranged from 48 to $68 \mathrm{yr}$.
TABLE 1. Biochemical test values in 19 patients with cirrhosis

\begin{tabular}{lcc}
\hline \multicolumn{1}{c}{ Biochemical test } & $\begin{array}{c}\text { Mean } \\
\text { (range) }\end{array}$ & Normal range \\
\hline Serum bilirubin ( $\mu \mathrm{mol} / \mathrm{L})$ & $32(7-115)$ & $2-17$ \\
Serum AST (IU/L) & $66(29-150)$ & $10-40$ \\
Serum alkaline phos- & $380(211-807)$ & $50-275$ \\
$\quad$ phatase (U/L) & & \\
Prothrombin index & $0.69(0.29-1.51)$ & $0.7-1.3$ \\
Serum sodium (mmol/L) & $137(130-144)$ & $136-147$ \\
Serum potassium (mmol/L) & $3.9(3.4-5.2)$ & $3.5-5.0$ \\
Serum creatinine ( $\mu \mathrm{mol} / \mathrm{L})$ & $85(55-136)$ & $49-121$ \\
Serum albumin & & \\
$\quad \mu m o l / L$ & $487(288-666)$ & $540-800$ \\
gm/L & $33.6(19.9-46)$ & $37-55$ \\
Hemoglobin (mmol/L) & $8.2(6.9-9.8)$ & women, $7.1-9.9 ;$ \\
& & men, 8.1-10.9 \\
\hline
\end{tabular}

All subjects consented to the study, which was approved by the Ethics Committee for Medical Research in Copenhagen. No complications or side effects were encountered.

Protocol. Cardiac output, plasma volume, blood volume, pressure measurements and assessment of ECBV were performed as specified in the following paragraphs. The "ideal" body weight $(I B W)$, expressed in kilograms of IBW $\left(\mathrm{kg}^{*}\right)$, was estimated as

$$
\text { IBW }\left(\mathrm{kg}^{*}\right)=(\mathrm{H}-100)-\frac{1}{4}(\mathrm{H}-150)
$$

where $H$ is body height in centimeters (8).

Plasma samples for determination of endogenous norepinephrine, epinephrine and ANF were obtained as described elsewhere $(1,5,7)$.

The above procedures were performed in a basal period and were repeated during $\beta$-adrenergic blockade $90 \mathrm{~min}$ after ingestion of propranolol $(80 \mathrm{mg})$. As a control of the time courses of arterial norepinephrine and epinephrine levels, ANF and ECBV, these variables were determined twice with the same time interval in other cirrhotic patients who were not receiving propranolol but were otherwise undergoing the same catheterization procedure. No significant changes were found.

Catheterization. All subjects were studied in the morning after overnight fasting and after at least $1 \mathrm{hr}$ in the supine position. Catheterization of the right atrium and the hepatic and renal veins was performed as described earlier $(2,5)$. A Cournand catheter (USCI; C.R. Bard Ireland Ltd., Galway, Ireland) or Swan-Ganz catheter (7F) (Baxter Healthcare Corp., Irvine, CA) was guided to the right atrium and hepatic and renal veins through the femoral route under fluoroscopic control while the patient was under local anesthesia. An indwelling polyethylene catheter was introduced through the femoral artery by the Seldinger technique, and the catheter tip was placed at the aortic bifurcation. Pressures were measured with a capacitance transducer (Simonsen \& Weel, Copenhagen, Denmark). The zero reference was the midaxillary level.

Determination of Flow and Volume. Total plasma volume, whole blood volume, and cardiac output were determined as described elsewhere $(1,2)$. ECBV was assessed according to the kinetic theory as cardiac output multiplied by the mean indicator transit time $(1,2,9-11)$. The latter is the mean time of indicator sojourn in the central vascular bed (9), determined as the time-weighted area under the arterial indicator curve and corrected for the arterial catheter transit time $(1,2)$. 
TABLE 2. ECBV and hemodynamic values in supine and fasting cirrhotic patients and controls

\begin{tabular}{|c|c|c|c|}
\hline Characteristics & $\begin{array}{c}\text { Cirrhotic patients } \\
\quad(n=18)\end{array}$ & $\begin{array}{l}\text { Controls } \\
(n=16)\end{array}$ & p Value \\
\hline ECBV (l) & $1.51 \pm 0.29$ & $1.81 \pm 0.40$ & $<0.02$ \\
\hline ECBV $\left(\mathbf{m l} / \mathbf{k g}^{*}\right)$ & $22.9 \pm 4.6$ & $27.2 \pm 6.8$ & $<0.05$ \\
\hline Mean transit time of central circulation (sec) & $14.0 \pm 4.1$ & $20.0 \pm 6.1$ & $<0.005$ \\
\hline Total blood volume (l) & $5.73 \pm 0.98$ & $5.45 \pm 1.15$ & NS \\
\hline Total blood volume (ml/kg*) & $81 \pm 15$ & $81 \pm 19$ & NS \\
\hline Cardiac output $(\mathrm{L} / \mathrm{min})$ & $6.81 \pm 1.7$ & $5.22 \pm 1.5$ & $<0.01$ \\
\hline Heart rate $\left(\min ^{-1}\right)$ & $77 \pm 11$ & $68 \pm 9$ & $<0.02$ \\
\hline \multicolumn{4}{|l|}{ Arterial blood pressure $(\mathrm{n}=18 ; \mathrm{mm} \mathrm{Hg})$} \\
\hline Systolic & $135 \pm 22$ & $141 \pm 22$ & NS \\
\hline Diastolic & $62 \pm 10$ & $71 \pm 13$ & $<0.05$ \\
\hline Mean & $84 \pm 16$ & $95 \pm 13$ & $<0.05$ \\
\hline
\end{tabular}

Data expressed as mean \pm S.D.; *expressed per kg estimated ideal body weight.

Catheter transit time was determined as catheter volume divided by catheter flow rate during blood sampling $(0.5 \mathrm{ml} / \mathrm{sec})$ (2).

As indicator, $5 \mu \mathrm{Ci}$ of ${ }^{125}$ I-labeled human serum albumin (Institute of Energy Technique, Kjeller, Norway) was injected quantitatively as a bolus through the venous catheter while the tip was located at the junction of the right atrium and the inferior vena cava. Arterial samples $(500 \mu \mathrm{l})$ were collected with a calibrated pump (Dich, Copenhagen, Denmark) every second for $60 \mathrm{sec}$. Standards and blood samples were counted in a well-type scintillation counter (LKB-Wallace, Stockholm, Sweden); at least 10,000 counts were recorded per sample. The coefficient of variation of duplicate determination of ECBV in six cirrhotic patients was $8.8 \%(2)$.

Plasma Catecholamines. Blood samples were collected from an artery and the right renal vein in ice-chilled tubes containing EGTA. Plasma was separated immediately from cells by centrifugation at $4^{\circ} \mathrm{C}$ and stored at $-70^{\circ} \mathrm{C}$ until it could be assayed. Plasma concentrations of endogenous norepinephrine and epinephrine were determined with an enzymatic isotope derivative technique described previously (12). The intraassay and interassay coefficients of variation were approximately $7 \%$ and $11 \%$ for norepinephrine and epinephrine, respectively.

ANF. Blood samples $(10 \mathrm{ml})$ were collected from an artery into ice-chilled tubes containing aprotinin $(5,000 \mathrm{KIU})$ and heparin (500 IU). Plasma was immediately separated from blood cells by centrifugation at $4^{\circ} \mathrm{C}$ and frozen $\left(-25^{\circ} \mathrm{C}\right)$ until it could be assayed. ANF in plasma was determined on RIA as described elsewhere $(13,14)$. The intraassay and interassay coefficients of variation were less than $10 \%$ and $15 \%$, respectively.

Statistical Evaluation. Paired and unpaired Student's $t$ tests and one-way ANOVA were used for group comparisons. Correlations were performed according to the least-squares method; $p<0.05$ was considered significant.

\section{RESULTS}

Basal Period. Results of assays for ECBV and other hemodynamic variables are summarized in Table 2 . The ECBV and mean transit time of the central circulation were significantly decreased in patients with cirrhosis compared with controls (ECBV: mean $=22.9 \mathrm{ml} / \mathrm{kg}^{*}$ in cirrhotic patients vs. $27.2 \mathrm{ml} / \mathrm{kg}^{*}$ in controls, $p<0.05$; mean transit time: $14 \mathrm{sec}$ in cirrhotic patients vs. $20 \mathrm{sec}$ in controls, $p<0.005$ ). The patients taking diuretic drugs had a slightly smaller mean ECBV than did those patients who were not taking diuretic drugs, but this difference was not statistically significant $(22.0 \pm 1.2$ $\mathrm{ml} / \mathrm{kg}^{*}$ (S.E.M.) vs. $24.2 \pm 1.9 \mathrm{ml} / \mathrm{kg}^{*}$, respectively; NS). ECBV was inversely correlated with increased hepatic venous pressure gradient in the patients $(r=-0.62$, $p<0.01$; Fig. 1). Total plasma volume and cardiac output were increased, whereas mean arterial blood pressure and systemic vascular resistance were decreased in the patient group (Table 2).

As shown in Table 3, arterial plasma norepinephrine levels were significantly increased in patients compared with levels in controls $(3.08 \mathrm{nmol} / \mathrm{L}$ vs. $1.36 \mathrm{nmol} / \mathrm{L}$; $\mathrm{p}<0.01$ ). The mean renal venous norepinephrine concentration in the cirrhotic patients was significantly higher than the mean arterial concentration (4.26 $\mathrm{nmol} / \mathrm{L}$ vs. $3.08 \mathrm{nmol} / \mathrm{L} ; \mathrm{n}=18, \mathrm{p}<0.001$ ) and significantly higher than the mean renal venous norepinephrine level in the controls $(4.26 \mathrm{nmol} / \mathrm{L}$ vs. 1.78 $\mathrm{nmol} / \mathrm{L} ; \mathrm{p}<0.01$ ). The cirrhotic patients had a mean arterial norepinephrine level that was inversely correlated with $\operatorname{ECBV}(r=-0.54, p<0.01$; Fig. 2A); patients with normal arterial values of norepinephrine (i.e., less than $2.2 \mathrm{nmol} / \mathrm{L} ; \mathrm{n}=8$ ) had a significantly higher mean ECBV than did patients with increased norepinephrine levels $(26.3 \pm 1.7$ vs. $21.4 \pm 0.9$; $\mathrm{n}=11, \mathrm{p}<0.02$ ). Renal venous norepinephrine level was also inversely correlated with ECBV in the patient group ( $r=-0.53, n=18, p<0.02$; Fig. 2B). Plasma epinephrine and ANF levels were normal in our cirrhotic patients (Table 3), and no significant relationship was found between ECBV and ANF concentration $(r=0.18$, NS; Fig. 3) or epinephrine level. 

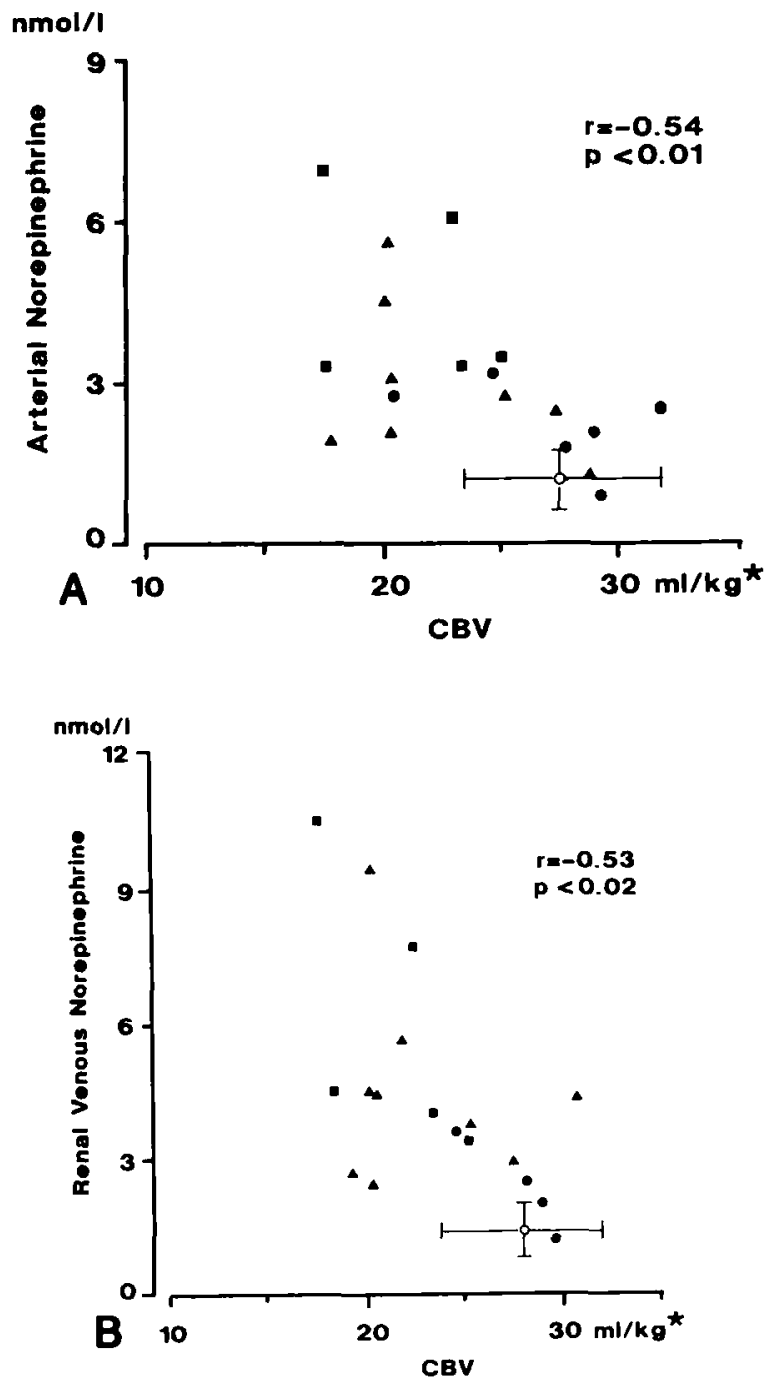

F1G. 2. (A) Relationship between ECBV and arterial plasma concentration of norepinephrine in patients with cirrhosis. Correlation analysis was only performed for patients with cirrhosis. (B) Relationship between ECBV and renal venous plasma concentration of norepinephrine in patients with cirrhosis. $O=$ mean \pm S.D. of controls; $\bullet=$ Child class $\mathrm{A} ; \boldsymbol{\Delta}=$ Child class $\mathrm{B} ; \mathbf{\square}=$ Child class $\mathrm{C}$.

B-Adrenergic Blockade. B-Adrenergic blockade produced a substantial decrease in heart rate and cardiac output $(-20 \%[p<0.001]$ and $-24 \%$ [p $<0.001]$, respectively; Table 4). The mean transit time of the central circulation increased significantly $(+28 \%$; p < 0.005), but the mean ECBV was not altered significantly after propranolol ingestion, except in six patients. These patients had a decrease in mean arterial blood pressure (from $85 \mathrm{~mm} \mathrm{Hg}$ to $69 \mathrm{~mm} \mathrm{Hg}$ ) and a decrease in mean ECBV (from $23.2 \mathrm{ml} / \mathrm{kg}^{*}$ to 20.6 $\mathrm{ml} / \mathrm{kg}^{*} ; \mathrm{p}<0.05$ ). The mean hepatic venous pressure gradient decreased (from 18.6 to $16.3 \mathrm{~mm} \mathrm{Hg} ; n=19$, $\mathrm{p}<0.01$ ), but no significant correlation with ECBV was seen after propranolol ingestion $(r=-0.13$; NS). A slight increase in the mean right atrial pressure (from $2.2 \mathrm{~mm} \mathrm{Hg}$ to $3.7 \mathrm{~mm} \mathrm{Hg} \mathrm{n}=14, \mathrm{p}<0.05$ ) was

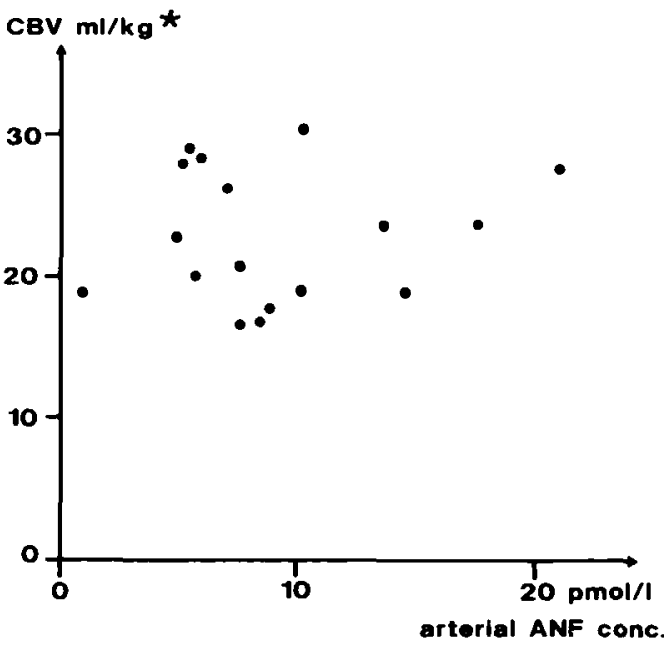

FiG. 3. Relationship between ECBV and arterial plasma concentration of ANF ( $r=0.18$; NS).
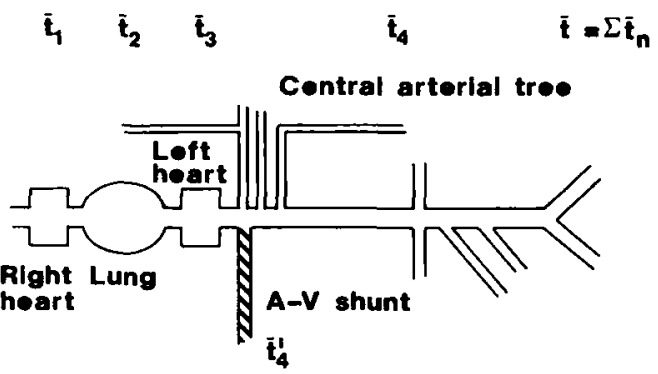

$\mathrm{ECBV}_{\mathrm{n}} 150 \mathrm{ml} 650 \mathrm{ml} 150 \mathrm{ml}$

$350 \mathrm{ml} \quad \mathrm{ECBV}=\Sigma \mathrm{CBV}_{\mathrm{n}}=1300 \mathrm{ml}$

FIG. 4. Schematic illustration of ECBV, consisting of the volumes of the heart cavities, the pulmonary vascular bed and the central arterial tree. $\bar{t}_{1}, \bar{t}_{2}, \bar{t}_{3}$ and $\bar{t}_{4}$ are mean transit times for right heart, lungs, left heart and central arterial tree, respectively; $\mathrm{\Sigma t}_{\mathrm{n}}=$ sum of individual transit times; $\mathrm{ECBV}_{\mathrm{n}}=$ segment of the central blood volume. Hatched area illustrates arteriovenous shunt. For details, see Appendix.

observed during $\beta$-adrenergic blockade. This change was positively correlated with the change in $\operatorname{ECBV}(r=0.44$, $\mathrm{p}=0.06)$.

Arterial norepinephrine and epinephrine levels increased significantly after propranolol ingestion (Table 4), but no significant correlation with ECBV was found. ANF did not change significantly and was not correlated with ECBV during $\beta$-adrenergic blockade; nor was any change in ANF, norepinephrine or epinephrine level correlated with change in ECBV.

\section{DISCUSSION}

The arterial plasma level of norepinephrine is an index of overall sympathetic nervous activity in patients with cirrhosis $(5,15-17)$. In this study, ECBV was inversely correlated with arterial norepinephrine concentration, which means that the more reduced the ECBV, the more enhanced the sympathetic nervous tone. This relationship may not be causal-for example, ECBV and 
TABLE 3. Circulating levels of catecholamines and ANF in supine, fasting patients with cirrhosis and in controls

\begin{tabular}{|c|c|c|c|}
\hline Catecholamines/ANF & $\begin{array}{c}\text { Cirrhotic patients } \\
(\mathrm{n}=19)\end{array}$ & $\begin{array}{l}\text { Controls } \\
(\mathbf{n}=9)\end{array}$ & p Value \\
\hline \multicolumn{4}{|l|}{ Norepinephrine } \\
\hline In arterial plasma $(\mathrm{nmol} / \mathrm{L})$ & $3.08 \pm 1.53^{a}$ & $1.36 \pm 0.36$ & $<0.01$ \\
\hline Epinephrine in arterial plasma ( $\mathrm{nmol} / \mathrm{L})$ & $0.43 \pm 0.27$ & $0.27 \pm 0.16$ & NS \\
\hline ANF in arterial plasma $(\mathrm{pmol} / \mathrm{L})$ & $8.9 \pm 4.9$ & $9.6 \pm 5.7^{c}$ & NS \\
\hline
\end{tabular}

aData expressed as mean \pm S.D

${ }^{b} \mathrm{n}=18$.

${ }^{c} \mathbf{n}=\mathbf{8}$.

TABLE 4. Effect of $\beta$-adrenergic blockade on hemodynamic values and neurohumoral markers in 19 cirrhotic patients

\begin{tabular}{|c|c|c|c|}
\hline \multirow[b]{2}{*}{ Characteristics } & \multicolumn{3}{|c|}{ Change from basal value } \\
\hline & Absolute ${ }^{a}$ & Percentage & p Value \\
\hline Heart rate $\left(\min ^{-1}\right)$ & $-15 \pm 9$ & -20 & $<0.001$ \\
\hline ECBV (1) & $-0.02 \pm 0.36$ & -1 & NS \\
\hline Mean transit time of central circulation (sec) & $+3.7 \pm 3.9$ & +28 & $<0.005$ \\
\hline Total blood volume (1) & $-0.15 \pm 0.80$ & -3 & NS \\
\hline Systemic vascular resistance, $\left(n=18 ; \mathrm{dyn} \cdot \mathrm{sec} / \mathrm{cm}^{5}\right)$ & $+209 \pm 180$ & +28 & $<0.01$ \\
\hline Right atrial pressure $(\mathrm{n}=14 ; \mathrm{mm} \mathrm{Hg})$ & $+1.5 \pm 1.6$ & +60 & $<0.05$ \\
\hline Hepatic venous pressure gradient $(\mathrm{mm} \mathrm{Hg}$ ) & $-2.3 \pm 3.7$ & -15 & $<0.01$ \\
\hline Arterial norepinephrine $(\mathrm{nmol} / \mathrm{L})$ & $+0.37 \pm 0.36$ & +13 & $<0.01$ \\
\hline Arterial epinephrine $(\mathrm{nmol} / \mathrm{L})$ & $+0.43 \pm 0.65$ & +90 & $<0.01$ \\
\hline Arterial ANF (pmol/L) & $+1.9 \pm 5.4$ & +21 & NS \\
\hline
\end{tabular}

ada expressed as mean \pm S.D.

norepinephrine level could both be related to progression of liver disease $(5,18)$. However, it should be borne in mind that a well-established reflex arc links volume receptors and baroreceptors to postganglionic sympathetic burst frequency in humans and animals $(19,20)$. It is thus likely that central vascular underfilling activates volume receptors and baroreceptors, thereby contributing to the enhanced sympathetic nervous activity found in patients with cirrhosis. Moreover, this study showed a significant inverse correlation between the size of the ECBV and the renal venous norepinephrine level. This finding suggests that the central underfilling contributes directly to enhanced sympathetic activity in the kidneys, because the level of renal venous norepinephrine is closely related to norepinephrine spillover from the kidney and thereby related to the rengl sympathetic nervous tone $(5,21,22)$. It is now well established that renal sympathetic overactivity contributes to the reduced renal blood flow and increased sodium and water retention in patients with decompensated cirrhosis $(4,16,23)$. Effects of diuretic drugs on sympathetic nervous activity and ECBV are modest and have been considered in detail elsewhere $(2,5)$.

In contrast to the significant relationship between decreased ECBV and enhanced sympathetic nervous tone, we found no relationship between ECBV and circulating level of ANF. ANF has been reported to be reduced, normal and increased in the presence of cirrhosis $(1,7,24-26)$. Arterial ANF concentration was normal in this study. Plasma ANF level is increased in patients with congestive heart failure and in subjects with volume expansion and increased atrial pressure $(27,28)$. It is low or normal in people with hypovolemia $(27,29)$. The normal ANF levels and the absence of correlation with ECBV found in our patients suggest that atrial volume is not affected substantially by ECBV reduction. This point of view is in keeping with recent reports by Rector et al. $(30,31)$, who actually found an insignificant decrease in right atrial volume $(-5 \mathrm{ml})$ and a significant increase in left atrial volume $(+16 \mathrm{ml})$ in patients with cirrhosis. Another possibility is that the presence of ascites alters spatial relationships in the heart $(32,33)$, thereby rendering the release of ANF more or less independent of the size of ECBV. Furthermore, decreased clearance of ANF in the presence of reduced release may also account for the unchanged plasma concentration. This possibility, however, seems less likely because recent reports suggest that clearance of ANF is normal in cirrhosis $(34,35)$.

The time sequence of the development of abnormal distribution of blood volume in cirrhotic patients is not known. In an experimental model of portal hypertension, Groszmann (36) recently showed that the initial event is reduced systemic vascular resistance. Cardiac output does not increase until plasma volume expansion 
has taken place. As further evidence of the importance of peripheral vasodilatation, it should be mentioned that normalization of sodium and water excretion may not only require expansion of the central blood volume but also normalization of the low arterial blood pressure (17).

$\beta$-Adrenergic blockade induced substantial changes in systemic vascular resistance and portal pressure. The decrease in the hepatic venous pressure gradient and the increase in systemic vascular resistance (both toward normal values) might be expected to cause an increase in ECBV $(1,2)$. Propranolol decreased cardiac output and increased right atrial pressure. However, in spite of these major hemodynamic alterations ECBV was almost unchanged and was decreased only in those patients who experienced decreases in mean arterial blood pressure. This indicates to us that arterial blood pressure is an important determinant for the size of ECBV and stresses the fact that ECBV includes the central parts of the arterial tree. Moreover, reduced arterial blood pressure may not only bring about reduced arterial blood volume but also a decrease in the volumes of the heart cavities and vascular bed of the lungs through decreased afterload (37). Finally, propanolol may modify ECBV by changing the circulating level of vasoactive factors; this may influence central vascular tone (18).

During $\beta$-adrenergic blockade, the inverse relationship between ECBV on one hand and hepatic venous pressure gradient, arterial norepinephrine level and renal venous norepinephrine level on the other hand disappeared. This may have been a result of direct action exerted by propranolol on the hepatic venous pressure gradient and on sympathetic nervous activity, whereas the alteration in ECBV may have been governed largely by changes in preload and afterload. A direct relationship was observed between the change in right atrial pressure and the change in ECBV after propranolol ingestion. In a previous study we found no relationship between ECBV size and right atrial pressure (2). In this context it should be recalled that the level of right atrial pressure relative to an external reference in the midaxillary line does not necessarily reflect the transmural atrial pressure and the filling of the central vascular bed. However, by relating the change in ECBV to the change in right atrial pressure we obtained a measurement independent of the external pressure reference.

Patients with cirrhosis have decreased systemic vascular resistance because of arteriolar dilatation and opening of arteriovenous shunts in almost all vascular territories $(4,38,39)$. The potential effect of these hemodynamic alterations on the assessment of the ECBV is considered in the appendix. As the appendix illustrates, evenly distributed peripheral vasodilatation or arteriovenous shunting in all vascular territories is not likely to influence determination of ECBV. Conversely, the presence of a large central arteriovenous shunt may result in a slightly overestimated value of ECBV. In a previous report, we considered the potential effects of intracardiac shunts and portopulmonary shunting on the determination of ECBV (2). Pulmonary shunts have no effect on the assessment of $\operatorname{ECBV}(2,40)$.

In conclusion, patients with cirrhosis are unable to maintain a normal size of central and arterial blood volume ("effective" blood volume). Reduced central and arterial blood volume most likely "unload" volume receptors and baroreceptors and thus provoke enhanced overall sympathetic nervous activity and increased sympathetic tone in the kidney. $\beta$-Adrenergic blockade resulted in substantial hemodynamic changes but only modest changes in the central and arterial blood volume. However, these changes were correlated with alterations in preload and afterload, indicating that central circulatory underfilling is an integral part of the hemodynamic derangement observed in cirrhosis.

Acknowledgments: We thank Dr. Rainer Arendt, Klinikum Grosshadern, University of Munich, for supplying antibodies for ANF determination and express our gratitude to the nurses and technicians of the Department of Clinical Physiology, Hvidovre University Hospital, and to Ms. Bente Henriksen for her excellent secretarial assistance.

\section{REFERENCES}

1. Henriksen JH, Schütten HJ, Bendtsen F, Warberg J. Circulating atrial natriuretic peptide (ANP) and central blood volume (ECBV) in cirrhosis. Liver 1986;6:361-368.

2. Henriksen JH, Bendtsen F, Sørensen TIA, Stadager C, RingLarsen H. Reduced central blood volume in cirrhosis. Gastroenterology 1989;97:1506-1513.

3. Arroyo V, Planas R, Gaya I, Deulofeu R, Rimola A, Perez-Ayuso $\mathrm{RM}$, Rivera $\mathrm{F}$, et al. Sympathetic nervous activity, reninangiotensin system and renal excretion of prostaglandin $E_{2}$ in cirrhosis: relationship to functional renal failure and sodium and water excretion. Eur J Clin Invest 1983;13:271-278.

4. Schrier RW, Arroyo V, Bernardi M, Epstein M, Henriksen JH, Rodés J. Peripheral arterial vasodilation hypothesis: a proposal for the initiation of renal sodium and water retention in cirrhosis. HEPATOLOGY 1988;8:1151-1157.

5. Henriksen JH, Ring-Larsen H, Kanstrup I-L, Christensen NJ. Splanchnic and renal elimination and release of catecholamines in cirrhosis: evidence of enhanced sympathetic nervous activity in patients with cirrhosis. Gut 1984;25:1034-1043.

6. Bichet D, Szatalowicz V, Chaimovitz C, Schrier RW. Role of vasopressin in abnormal water excretion in cirrhotic patients. Ann Intern Med 1982;96:413-417.

7. Gerbes AL, Arendt RM, Paumgartner G. Atrial natriuretic factor: possible implications in liver disease. J Hepatol 1987;5:123-132.

8. Liebermann FL, Reynolds TB. Plasma volume in cirrhosis of the liver: its relation to portal hypertension, ascites, and renal failure. J Clin Invest 1967;46:1297-1308.

9. Lassen NA, Perl W. Tracer kinetics methods in medical physiology. New York: Raven Press, 1979:76-112.

10. Schlant RC, Novack P, Kraus WL, Moore CB, Haynes FW, Dexter L. Determination of central blood volume: comparison of StewartHamilton method with direct measurements in dogs. Am J Physiol 1959;196:499-501.

11. Rowell LB. Cardiovascular adjustment to thermal stress. In: Shephard JT, Abboud FM, eds. Handbook of physiology. Baltimore: Williams \& Wilkins, 1983:967-1023.

12. Christensen NJ, Vestergaard $P$, Sørensen $T$, Rafaelsen $O J$. Cerebrospinal fluid adrenaline and noradrenaline in depressed patients. Acta Psychiatr Scand 1980;61:1872-82.

13. Gerbes AL, Wernze H, Arendt RM, Riedel A, Sauerbruch T, Paumgartner $P$. Atrial natriuretic factor (ANF) and renin- 
aldosterone in volume regulation of patients with cirrhosis. HEPATOLOGY 1989;9:417-422.

14. Arendt RM, Gerbes AL, Ritter D, Ridder D, Stangl E. Molecular weight heterogeneity of plasma-ANF in cardiovascular disease. Klin Wochenschr 1986;64(suppl VI):97-102.

15. Bichet DG, Van Putten VJ, Schrier EW. Potential role of increased sympathetic activity in impaired sodium and water retention in cirrhosis. N Engl J Med 1982;309:1152-1157.

16. Henriksen JH, Ring-Larsen H, Christensen NJ. Sympathetic nervous activity in cirrhosis: a survey of plasma catecholamine studies. J Hepatol 1984;1:55-65.

17. Nicholls KM, Shapiro MD, Van Putten VJ, Klunge R, Chung H-M, Bichet DG, Schrier RW. Elevated plasma norepinephrine concentrations in decompensated cirrhosis: association with increased secretion rates, normal clearance rates, suppressibility by central blood volume expansion. Circ Res 1985;56:457-461.

18. Bendtsen F, Henriksen JH, Sørensen TIA, Christensen NJ. Effect of oral propranolol on circulating catecholamines in cirrhosis: relationship to severity of liver disease and splanchnic haemodynamies. J Hepatol 1990;10:198-204.

19. Sagawa K. Baroreflex control of systemic arterial pressure and vascular bed. In: Shephard JT, Abboud FM, eds. Handbook of physiology. Baltimore: Williams \& Wilkins, 1983:453-496.

20. Kostreva DR. Venous low-pressure baro-receptor reflexes arising from the liver, spleen, mesenteric bed, and limb veins. In: Epstein M, ed. The kidney in liver disease. 3rd ed. Baltimore: Williams \& Wilkins, 1988:456-68.

21. Kopp U, Bradley T, Hjemsdahl P. Renal venous outflow and urinary excretion of norepinephrine, epinephrine and dopamine during graded renal nerve stimulation. Am J Physiol 1983;244: E52-E60.

22. Henriksen JH, Christensen NJ, Ring-Larsen H. Continuous infusion of tracer norepinephrine may miscalculate unidirectional nerve uptake of norepinephrine in humans. Circ Res 1989;65: 388-395.

23. Ring-Larsen $H$. Hepatic nephropathy related to haemodynamics. Liver 1983;3:265-289.

24. Bonkovsky H, Hartle DK, Mellen BG, Kutner M, Galambos JT. Plasma concentrations of immunoreactive atrial natriuretic peptide in hospitalized cirrhotic and noncirrhotic patients: evidence for a role of deficient atrial natriuretic peptide in pathogenesis of cirrhotic ascites. Am J Gastroenterol 1988;83:531-535.

25. Salerno F, Badalamenti S, Moser P, Lorenzano E, Pierluigi I, Dioguardi N. Atrial natriuretic factor in cirrhotic patients with tense ascites. Gastroenterology 1990;98:1063-1070.

26. Epstein M. Atrial natriuretic factor in patients with liver disease. Am J Nephrol 1989;9:89-100.

27. Gerbes AL, Arendt RM, Gerzer R, Schnizer W, Jüngst D, Paumgartner G, Wernze $\mathrm{H}$. Role of atrial natriuretic factor, cyclic GMP and the renin-aldosterone system in acute volume regulation of healthy human subjects. Eur J Clin Invest 1988;18:425-429.

28. Campbell P, Skorecki K, Logan A, Wong P-Y, Leung WM Greig P, Blendis LM. Acute effects of peritoneovenous shunting on plasma atrial natriuretic peptide in cirrhotic patients with massive refractory ascites. Am J Med 1988;84:112-119.

29. Goetz KL. Physiology and pathophysiology of atrial peptides. Am J Physiol 1988;254:E1-E15.

30. Rector WG Jr, Hossack KF. Pathogenesis of sodium retention complicating cirrhosis: is there room for diminished "effective" arterial blood volume? Gastroenterology 1988;95:1658-1663.

31. Rector WG Jr, Adair $O$, Hossack KF, Rainguet $S$. Arterial volume in cirrhosis: relationship to blood volume and plasma concentration of atrial natriuretic factor. Gastroenterology 1990;99: 766-770.

32. Panos MZ, Moore K, Vlavianos $P$, Chambers JB, Anderson JV, Gimson AES, Slater JDH, et al. Single, total paracentesis for tense ascites: sequential hemodynamic changes and right atrial size. HEPATOLOGY 1990;11:662-667.

33. Keller H, Bezjak V, Stegaru B, Buss J, Holm E, Heene DL. Ventricular function in cirrhosis and portasystemic shunt: a two-dimensional echocardiographic study. HEPATOLOGY 1988;8: 658-662.
34. Henriksen JH, Bendtsen F, Schütten HJ, Warberg J. Hepaticintestinal disposal of endogenous human alpha atrial natriuretic factor $_{9-126}$ in patients with cirrhosis. Am J Gastroenterol 1990; 85:1155-1159.

35. Gerbes AL, Vollmar AM. Degradation and clearance of atrial natriuretic factors (ANF). Life Sci 1990;47:1173-1180.

36. Groszmann RJ. Splanchnic vasodilation in portal hypertension: mechanism consequences on systemic circulation. In: Santilini P, Arias IM, Sokrier RW, eds. Liver diseases and renal complications. New York: Raven Press, 1990:125-183.

37. Gossmann W. Evaluation of systolic and diastolic function of the myocardium. In: Gossmann W, ed. Cardiac catheterization and angiography. Philadelphia: Lea \& Fibiger, 1986:301-319.

38. Sherlock S. Vasodilatation associated with hepatocellular disease: relation to functional organ failure. Gut 1990;31:365-367.

39. Bosch J, Ginës P, Arroyo V, Navasa M, Rodés J. Hepatic and systemic hemodynamics and the neurohumeral system in cirrhosis. In: Epstein M, ed. The kidney in liver disease. Baltimore: Williams \& Wilkins, 1988:286-305.

40. Rodriguez-Roisin R, Roca J, Agusti AG, Mastai R, Wagner PD, Bosch J. Gas exchange and pulmonary vascular reactivity in patients with liver cirrhosis. Am Rev Respir Dis 1987;135:10851092.

\section{APPENDIX}

Determination of ECBV may be influenced by circulatory shunts (2). Patients with cirrhosis have decreased peripheral vascular resistance; this may be due in part to the presence of systemic arteriovenous shunts $(4,46$, 47). The influence of general arteriolar vasodilatation and arteriovenous shunting on the determination of ECBV is noted below. The effect of a shunt is discussed in relation to the fundamental kinetic equation: volume $=$ mean transit time $(\overline{\mathrm{t}}) \times$ flow (12).

Example A. Assuming that cardiac output $(\mathrm{CO})$ is $6.0 \mathrm{~L} / \mathrm{min}$ and the parts of ECBV are $150 \mathrm{ml}, 650 \mathrm{ml}$, $150 \mathrm{ml}$ and $350 \mathrm{ml}$ for right heart, lungs, left heart and central arterial tree, respectively (see Fig. 4), the segmental mean transit times $\left(\bar{t}_{n}\right)$ will be $\overline{\mathrm{t}}_{1}=60 \times$ $0.150 / 6.0=1.5 \mathrm{sec} ; \bar{t}_{2}=6.5 \mathrm{sec} ; \bar{t}_{3}=1.5 \mathrm{sec} ;$ and $\bar{t}_{4}=3.5$ sec. The sum of segmental mean transit times $\left(\Sigma \bar{t}_{n}\right)=1.5 \mathrm{sec}+6.5 \mathrm{sec}+1.5 \mathrm{sec}+3.5 \mathrm{sec}=$ $13.0 \mathrm{sec}$, and thereby $\mathrm{ECBV}=\Sigma \overline{\mathrm{t}}_{\mathrm{n}} \cdot \mathrm{CO}=13.0 \cdot 6.0$. $10^{3} / 60=1,300 \mathrm{ml}$. This value is equal to the sum of segmental central blood volumes $\mathrm{EECBV}_{\mathbf{n}}=$ $150 \mathrm{ml}+650 \mathrm{ml}+150 \mathrm{ml}+350 \mathrm{ml}=1,300 \mathrm{ml}$.

Example $B$. It may be assumed that peripheral vascular resistance is decreased because of widespread arteriolar dilatation or the opening of numerous arteriovenous shunts in all vascular territories, which are assumed to be evenly distributed in all systemic vascular areas. If $\mathrm{CO}$ increases to $9.0 \mathrm{~L} / \mathrm{min}$, the segmental transit times will be $\bar{t}_{1}=6.0 \cdot 0.150 / 9.0=1.0 \mathrm{sec} ; \bar{t}_{2}=$ $4.33 \mathrm{sec} ; \overline{\mathrm{t}}_{3}=1.0 \mathrm{sec} ;$ and $\overline{\mathrm{t}}_{4}=2.33$ sec. Hence $\Sigma \overline{\mathrm{t}}_{\mathrm{n}}=1.0 \mathrm{sec}+4.33 \mathrm{sec}+1.0 \mathrm{sec}+2.33 \mathrm{sec}=8.66$ sec and $\mathrm{ECBV}=\Sigma \overline{\mathrm{t}}_{\mathrm{n}} \cdot \mathrm{CO}=8.66 \cdot 9.0 \cdot 10^{3} / 60=1,299$ $\mathrm{ml}$. Here also is agreement between ECBV as determined from $\bar{t}$ and cardiac output and that determined from the sum of the volumes in the single segments ( $\Sigma E C B V$ ), even though $\bar{t}$ decreased from $13.0 \mathrm{sec}$ to 8.66 sec because of the hyperkinetic circulation.

Example C. As another example it may be assumed that hyperdynamic circulation is due to the presence of 
a large arteriovenous shunt with a flow of $3.0 \mathrm{~L} / \mathrm{min}$ (Fig. 4). In this case, $\mathrm{CO}$ also increases from 6.0 to $9.0 \mathrm{~L} / \mathrm{min}$. As in the foregoing example, $\overline{\mathrm{t}}_{1}=1.0 \mathrm{sec} ; \overline{\mathrm{t}}_{2}=4.33 \mathrm{sec}$; and $\bar{t}_{3}=1.0 \mathrm{sec}$. In contrast, only $6.0 \mathrm{~L} / \mathrm{min}$ passes through the nonshunt segments of the peripheral circulation. Thus $\bar{t}_{4}$ will be the same size as it is in example A: $\bar{t}_{4}=3.5$ sec. Consequently, $\overline{\mathbf{t}}_{\mathrm{n}}=1.0$ $\mathrm{sec}+4.33 \mathrm{sec}+1.0 \mathrm{sec}+3.5 \mathrm{sec}=9.83 \mathrm{sec}$, a value larger than that in example $B(8.66 \mathrm{sec})$. ECBV = $\Sigma \overline{\mathrm{t}}_{\mathrm{n}} \cdot \mathrm{CO}=9.83 \cdot 9.0 \cdot 10^{3} / 60=1,475 \mathrm{ml}$. This value is larger than $\Sigma E_{C B C}=150 \mathrm{ml}+650 \mathrm{ml}+150$ $\mathrm{ml}+300 \mathrm{ml}=1,300 \mathrm{ml}$. This is because here the volume of blood contained in the arterial tree up to points that are temporally equidistant from the heart to the aortic bifurcation includes a "shunt volume" $=\overline{\mathrm{t}}_{4}{ }^{\prime} \cdot$ shunt flow $=3.5 \cdot 3.0 \cdot 10^{3} / 60=175 \mathrm{ml}$. If the shunt is centrally located and the shunt flow is high, the shunt volume may include parts of the blood volume located on the venous side of the circulation.

In conclusion, ECBV, as determined with our method, is not likely to be influenced by widespread arteriolar dilatation or opening of arteriovenous shunts in almost all vascular territories. In contrast, our method may overestimate the actual value of the ECBV in the presence of a distinct systemic arteriovenous shunt. The size of the overestimation will depend on the size of the shunt flow relative to $\mathrm{CO}$ and on the location of the shunt. More centrally located shunts will lead to more overrated values for ECBV than will more peripherally located shunts, other factors being equal. However, as illustrated in example $\mathrm{C}$, the overestimation $(175 / 1,475=12 \%)$ is relatively modest, even in the presence of a relatively high flow $(3.0 \mathrm{~L} / \mathrm{min} / 6.0$ $\mathrm{L} / \mathrm{min}=\mathbf{5 0 \%}$ ) in a centrally located shunt. 